\title{
Clinical comparison between patients with selective immunoglobulin A deficiency and other primary immunodeficiencies
}

\author{
Natalia A. Lozano, M.D., ${ }^{a}$ Alejandro Lozano, M.D., ${ }^{a}$ Laura V. Sasia, M.D., Ricardo J. Saranz, M.D., ${ }^{a}$ \\ María Fernanda Agresta, M.D., ${ }^{a}$ María del Pilar Bovina Martijena, M.D., ${ }^{a}$ Luciano Ianiero, M.D., ${ }^{a}$ and \\ Andrés R. Grenat, M.D. ${ }^{a}$
}

\begin{abstract}
Primaryimmunodeficiencies(PID) arelow-prevalencediseases. There are warning signs that may raise clinical suspicion. The objectives of this study were to describe the clinical characteristics and warning signs of patients with PID and to compare the clinical differences between selective immunoglobulin A (IgA) deficiency and other PIDs. Eighty-nine patients were studied; their median age at the time of diagnosis was 6 years old (4.08-11.67). Fifty-three (59.5\%) patients were male. Fifty-four $(60.7 \%)$ patients had selective IgA deficiency, and $35(39.3 \%)$ had other PIDs. The main clinical manifestations were rhinopharyngitis in $65(73.03 \%)$ patients and atopy in 39 (43.82\%). Twenty- four (26.97\%) patients showed warning signs, and none had selective IgA deficiency. Patients with other PIDs had a higher incidence of lower respiratory tract infection, sepsis, skin infections, mucocutaneous candidiasis, dental alterations, cardiovascular malformations, angioedema, hospitalizations and death. Ten $(28.57 \%)$ patients received intravenous gammaglobulin, 15 (42.85\%) antibiotic prophylaxis, and $2(2.24 \%)$ antifungal prophylaxis.

Key words: respiratory tract infections, gammaglobulins, immunodeficiency syndromes, IgA deficiency.
\end{abstract}

http:/ /dx.doi.org/10.5546/aap.2015.eng.141

\section{INTRODUCTION}

Primary immunodeficiencies (PID) are a heterogeneous group of diseases related to more than 200 genetic defects that affect the immune system. ${ }^{1,2}$

It is difficult to establish the prevalence of these diseases given regional variabilities and

a. Department of Allergy and Immunology of Clínica Universitaria Reina Fabiola. Chair of Immunology, School of Medicine, Universidad Católica de Córdoba, Argentina.

E-mail Address:

Natalia A. Lozano, M.D.: nalozano@yahoo.com

Funding:

Clínica Universitaria Reina Fabiola. School of Medicine, Universidad Católica de Córdoba.

Conflict of Interest: None.

Received: 6-13-2014

Accepted: 11-21-2014 the clinical and laboratory heterogeneity of the different conditions. Their prevalence is low (1/10 000 to $1 / 500000$ live births). ${ }^{1,3-5}$ The most common PIDs are antibody deficiencies, including the selective immunoglobulin $\mathrm{A}(\operatorname{Ig} \mathrm{A})$ deficiency, with a prevalence of $1 / 143$ to $1 / 20000$ live births. $3,4,6$

The latest updated PID classification divides them into nine classes depending on the affected immune system compartment. ${ }^{2}$ The presumptive diagnosis of PIDs is based on ten warning signs established by the Jeffrey Modell Foundation. ${ }^{7,8}$ However, some immunodeficiencies may present few or no warning signs.

The diagnosis is established as per the criteria defined by the European Society for Immunodeficiencies (ESID) and the PanAmerican Group for Immunodeficiency (PAGID), which classify diagnosis as possible, probable or definitive. ${ }^{9,10}$

Although there is molecular information on these conditions, many patients remain undiagnosed and/or are diagnosed at a later stage resulting, as a consequence, in an adverse clinical outcome. ${ }^{11}$

The objectives of this study are to describe the clinical characteristics of patients diagnosed with PID, analyze the presence of warning signs and compare the clinical manifestations between patients with selective IgA deficiency and other PIDs.

\section{POPULATION AND METHODS}

The Department of Allergy and Immunology of Clínica Universitaria Reina Fabiola has established study protocols for patients with suspicion of PID based on international guidelines. ${ }^{1}$ Studies vary depending on the affected immune system compartment.

Patients were assessed for warning signs of PID according to the criteria established by the Jeffrey Modell Foundation. ${ }^{7,8}$ These make up a clinical tool that allows to suspect which patients have a higher chance of developing a 
PID. Warning signs are as follows: 4 or more new ear infections in a year; 2 or more serious sinus infections in a year; 2 or more months of antibiotic treatment; 2 or more pneumonias in a year; failure to thrive; recurrent deep skin abscesses; persistent thrush in mouth or fungal skin infections; need for intravenous antibiotics; 2 or more deep-seated infections (including septicemia); and a family history of PID.

The study was retrospective, observational, and analytical.

Patients were included if they were part of the PID database of the Department of Allergy and Immunology and had a diagnosis of probable or definitive PID ${ }^{9,10}$ (Table 1) and they were classified according to the categories established in the latest classification. ${ }^{2}$ Patients were divided into two groups: selective IgA deficiency and other PIDs.

Patients who had a diagnosis of possible PID and secondary immunodeficiencies were excluded.

\section{Ethical considerations}

The study complied with the Declaration of Helsinki and the Good Clinical Practice guidelines established by the Drug, Food and Technology Administration of Argentina (Administración Nacional de Medicamentos, Alimentos y Tecnología Médica, ANMAT), Provincial Law No. 9694 referring to research on human beings, and Law No. 25326 regarding personal data protection. The study was approved by the Institutional Ethics Committee.

\section{Statistical analysis}

Outcome measures and comparisons were analyzed descriptively using an independent $\chi^{2}$ test for qualitative outcome measures and a Mann-Whitney test for quantitative outcome measures. A $p$ value $<0.05)$ was considered statistically significant.

\section{RESULTS}

Eighty-nine patients with PID were evaluated. Their overall characteristics are shown in Table 2. The main clinical manifestations were upper and lower respiratory tract infections and allergic diseases (Figure 1). Candidiasis was observed in patients with immune dysregulation alterations and innate immune defects. A history of hospitalization was observed in 37 (41.6\%) patients, and $5(5.62 \%)$ died as a result of their immunodeficiency.

Warning signs of PID were described for 24 $(26.97 \%)$ patients. These were: 4 or more new ear infections in a year ( 5 patients); 2 or more serious sinus infections in a year (6 patients); 2 or more months of antibiotic treatment (9 patients); 2 or more pneumonias in a year (14 patients); failure to thrive (5 patients); recurrent deep skin abscesses (2 patients); persistent thrush in mouth (4 patients); need for intravenous antibiotics (15 patients); deep-seated infections (3 patients); and a family history of PID (9 patients).

None of the patients had a history of consanguinity.

Prescribed treatments were as follows: intravenous gammaglobulin in 10 (11.24\%) patients, all of whom were in the predominantly antibody deficiency group (X-linked agammaglobulinemia, common variable immunodeficiency, and antibody response deficiency); antibiotic prophylaxis in $16(17.98 \%)$ patients (STAT5b deficiency, ataxia-telangiectasia, hyper IgE syndrome, Wiskott-Aldrich

TABLE 1. Diagnostic criteria for primary immunodeficiencies (ESID-PAGID) ${ }^{9}$

\begin{tabular}{ll} 
Diagnostic category & \multicolumn{1}{c}{ Definition } \\
\hline Definitive & Patients with a causative molecular-genetic diagnosis (genetic failure, absence of \\
& mRNA or protein causative of primary immunodeficiency). \\
& - Patients in this category have a probability at over $98 \%$ of keeping the same diagnosis \\
& in the following 20 years. \\
\hline Probable & Patients diagnosed by phenotype: clinical and/or laboratory characteristics compatible \\
& with primary immunodeficiency but without the identification of a causative genetic \\
& failure. \\
& Patients in this category have a probability at over $85 \%$ of keeping the same diagnosis in \\
& the following 20 years. \\
\hline Possible & Patients with some but not all clinical and/or laboratory characteristics compatible with \\
& primary immunodeficiency. . \\
\hline
\end{tabular}


TABLE 2. Demographic characteristics by group of primary immunodeficiency ${ }^{* * *}$

\begin{tabular}{|c|c|c|c|c|c|c|c|}
\hline & $\mathbf{N}$ & $\begin{array}{c}\text { Definitive } \\
\text { diagnostic } \\
\text { criterion } \\
\end{array}$ & $\begin{array}{c}\text { Female } \\
\text { sex } \\
(\%)\end{array}$ & $\begin{array}{c}\text { Age of } \\
\text { symptom } \\
\text { onset (years old) }\end{array}$ & $\begin{array}{c}\text { Age at } \\
\text { consultation } \\
\text { (years old) }\end{array}$ & $\begin{array}{c}\text { Age at } \\
\text { Dx } \\
\text { (years old) } \\
\end{array}$ & $\begin{array}{c}\text { Delay between } \\
\text { symptom onset } \\
\text { and Dx (years) }\end{array}$ \\
\hline $\begin{array}{l}\text { Total number of patients } \\
\text { with PID }\end{array}$ & 89 & $59 / 89$ & $36 / 89$ & $3(1-5)^{* *}$ & $\begin{array}{c}6 \\
(4.08-11.67)^{* *}\end{array}$ & $\begin{array}{c}6 \\
(4.08-11.67)^{* *}\end{array}$ & $\begin{array}{c}2.83 \\
(1.08-5.83)^{* *}\end{array}$ \\
\hline Combined ID & $1 / 89$ & $1 / 1$ & $1 / 1$ & 1.33 & 12 & 12 & 10.67 \\
\hline $\begin{array}{l}\text { Well-defined ID } \\
\text { syndrome }\end{array}$ & $8 / 89$ & $2 / 8$ & $3 / 8$ & $\begin{array}{c}1 \\
(0.37-1.27)^{* *}\end{array}$ & $\begin{array}{c}5.04 \\
(2.37-6.5)^{* *}\end{array}$ & $\begin{array}{c}3.25 \\
(2.18-4)^{* *}\end{array}$ & $\begin{array}{c}2.13 \\
(1.31-2.85)^{* *}\end{array}$ \\
\hline $\begin{array}{l}\text { Predominantly } \\
\text { antibody deficiencies* }\end{array}$ & $71 / 89$ & $50 / 71$ & $25 / 71$ & $\begin{array}{c}3 \\
(1.5-5)^{* *}\end{array}$ & $\begin{array}{c}6.08 \\
(4.33-11)^{* *}\end{array}$ & $\begin{array}{c}6.41 \\
(4.6-11.04)^{* *}\end{array}$ & $\begin{array}{c}3 \\
(1.04-5.79)^{* *}\end{array}$ \\
\hline $\begin{array}{l}\text { Diseases of immune } \\
\text { dysregulation }\end{array}$ & $1 / 89$ & $1 / 1$ & $1 / 1$ & 2 & 2.83 & 4.67 & 2.67 \\
\hline Phagocyte defects & $1 / 89$ & $0 / 1$ & $1 / 1$ & 10 & 12.5 & 13 & 3 \\
\hline $\begin{array}{l}\text { Innate immunity } \\
\text { defects }\end{array}$ & $2 / 89$ & $0 / 2$ & $2 / 2$ & $\begin{array}{c}1.25 \\
(0.87-0.95)^{* *}\end{array}$ & $\begin{array}{c}1.25 \\
(1.21-1.29)^{* *}\end{array}$ & $\begin{array}{c}2.83 \\
(2.25-3.41)^{* *}\end{array}$ & $\begin{array}{c}1.92 \\
(1.38-2.46)^{* *}\end{array}$ \\
\hline $\begin{array}{l}\text { Complement } \\
\text { deficiency }\end{array}$ & $5 / 89$ & $5 / 5$ & $2 / 2$ & $\begin{array}{c}5 \\
(4-6)^{* *}\end{array}$ & $\begin{array}{c}36 \\
(15.42-50)^{* *}\end{array}$ & $\begin{array}{c}36 \\
(15.42-50)^{* *}\end{array}$ & $\begin{array}{c}32 \\
(2-45)^{* *}\end{array}$ \\
\hline
\end{tabular}

ID: immunodeficiency; PID: primary immunodeficiency; Dx: diagnosis.

* 54/71 are patients diagnosed with selective IgA deficiency.

** Median (Q1-Q3).

*** There were no patients diagnosed with PID corresponding to autoinflammatory disorders and PID phenocopies.

FIGURE 1. Clinical manifestations of patients with selective immunoglobulin A deficiency and other primary immunodeficiencies

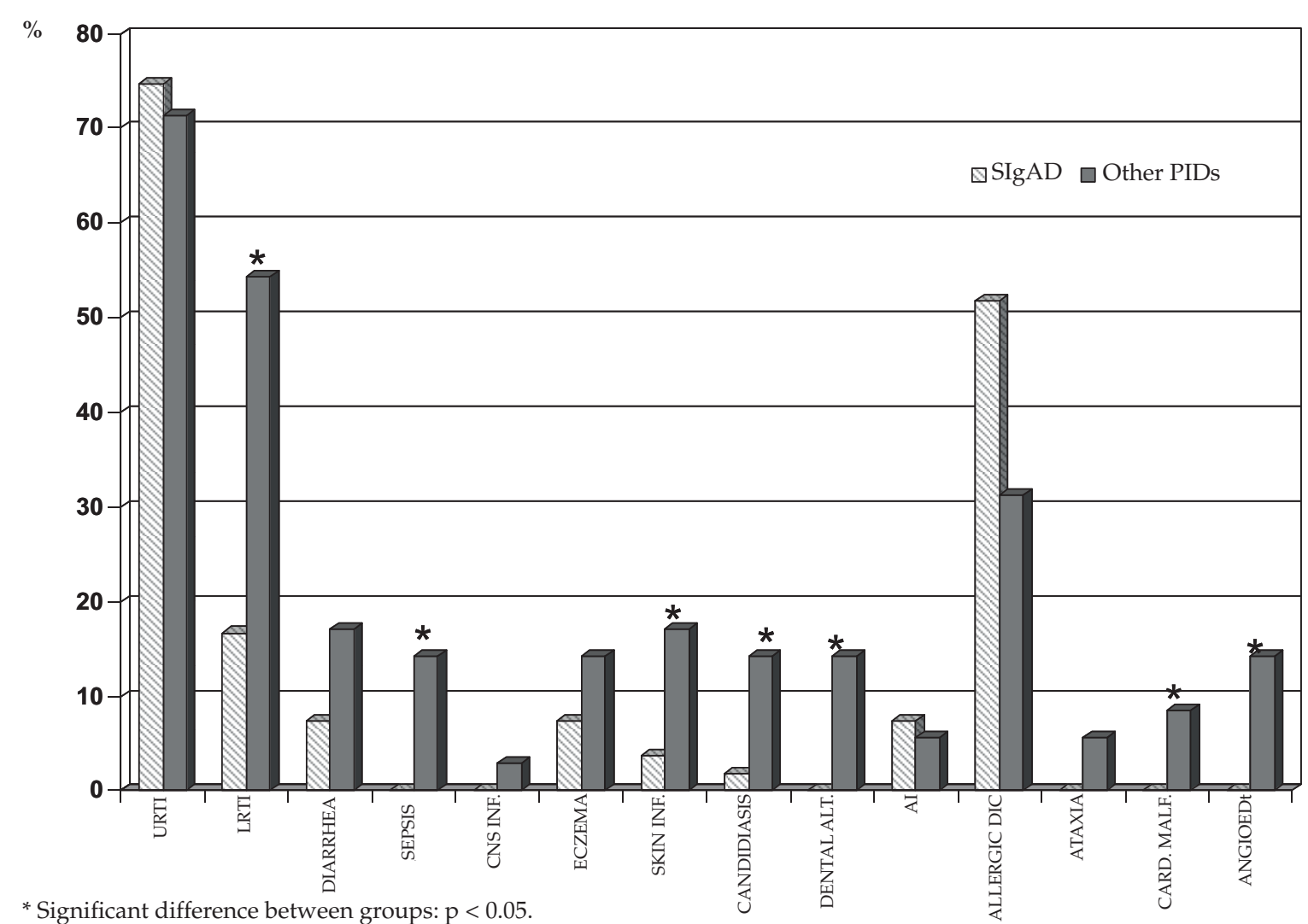

URTI: upper respiratory tract infection; LRTI: lower respiratory tract infection; CNS inf.: central nervous system infection; AI: autoimmunity; allergic dis.: allergic disease; card. malf.: cardiovascular malformation; angioed: angioedema; SIgAD: selective IgA deficiency; PID: primary immunodeficiency. 
syndrome, X-linked agammaglobulinemia, common variable immunodeficiency, transient hypogammaglobulinemia of infancy, IgG2 subclass deficiency, selective IgA deficiency, and chronic granulomatous disease ); and antifungal prophylaxis in $2(2.24 \%)$ patients (chronic granulomatous disease and common variable immunodeficiency).

Male sex was predominant in both groups; there were $33(61.11 \%)$ male patients in the selective IgA deficiency group and 20 (57.14\%) in the other PID group.

The general characteristics of each group are described in Table 3.

More manifestations of allergic disease were observed in the selective $\operatorname{Ig}$ A deficiency group than in the other PID group [28 patients $(51.85 \%)$ and 11 patients $(31 \%)$, respectively]; statistical differences were not significant $(p=0.0578)$ (Figure 1).

In our population, autoimmune diseases were observed in $4 / 54(7.4 \%)$ patients in the selective IgA deficiency group, and in $2 / 35(5.7 \%)$ patients in the other PID group (Figure 1).

\section{DISCUSSION}

An early diagnosis of PIDs allows to provide an initial treatment that will improve patients' quality of life and health costs. Therefore, the pediatrician's clinical suspicion plays a critical role for a timely diagnosis and referral. ${ }^{12}$

The prognosis of PIDs is associated with an early diagnosis, which allows to initiate an early treatment, and to the specific disease, which may severely affect children and have an impact on their clinical course. One of the diagnostic landmarks are warning signs established by the Jeffrey Modell Foundation, ${ }^{8}$ which are a key tool when these conditions are suspected.

Most PIDs are diagnosed as predominantly antibody deficiencies. ${ }^{3,4,13}$ Selective IgA was more prevalent, ${ }^{14,15}$ as observed in other studies.

In contrast to the data found in the bibliography, we observed a high percentage of patients with a positive family history of PIDs, and none of the included patients had a history of consanguinity. ${ }^{4}$ Such absence of consanguinity may be attributed to our small sample size.

For patients with a definitive diagnosis of PID, it is recommended to study the entire family based on the heritage pattern of the diagnosed deficiency.

The median age of symptom onset and PID diagnosis was lower than that observed in other

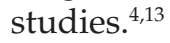

As other authors, ${ }^{4}$ we found that male sex was slightly more predominant.

Most patients with a deep-seated immune

TABLA 3. Comparison of characteristics between patients with selective immunoglobulin A deficiency and other primary immunodeficiencies

\begin{tabular}{lccc}
\hline & $\begin{array}{c}\text { Selective IgA } \\
\text { deficiency (n: 54) }\end{array}$ & $\begin{array}{c}\text { Other PIDs } \\
\text { (n: 35) }\end{array}$ & P \\
\hline $\begin{array}{l}\text { Age at symptom onset } \\
\text { (median - Q1-Q3) }\end{array}$ & $3.25(2-5)$ & $1.50(0.83-4)$ & 0.0167 \\
$\begin{array}{l}\text { Age of first medical consultation } \\
\text { (median - Q1-Q3) }\end{array}$ & $6.59(4.83-11)$ & $5.17(2.17-15.42)$ & 0.1670 \\
$\begin{array}{l}\text { Age at diagnosis } \\
\text { (median - Q1-Q3) }\end{array}$ & $6.88(5-11)$ & $4(2.58-15.42)$ & 0.0260 \\
$\begin{array}{l}\text { Time between symptom onset and Dx } \\
\text { (median - Q1-Q3) }\end{array}$ & $3.50(1.08-5.75)$ & $2.42(1-6)$ & 0.8271 \\
WS+ (\%) & $0(0)$ & $24(68.57)$ & $<0.000$ \\
$\begin{array}{l}\text { Number of WS+ } \\
\text { (median - Q1-Q3) }\end{array}$ & $0(0-0)$ & $2(0-3)$ & $<0.0001$ \\
IV gammaglobulin (\%) & $0(0)$ & $10(28.57)$ & $<0.000$ \\
Antibiotic prophylaxis (\%) & $1(1.85)$ & $15(42.85)$ & $<0.000$ \\
Antifungal prophylaxis (\%) & $0(0)$ & $2(5.71)$ & 0.1519 \\
Hospitalizations (\%) & $13(24.07)$ & $24(68.6)$ & $<0.000$ \\
Deceased patients (\%) & $0(0)$ & $5(14.3)$ & 0.0043 \\
\hline
\end{tabular}

PID: primary immunodeficiency; Dx: diagnosis; WS: warning signs; IgA: inmunoglobulin A; IV: intravenous. 
deficiency had warning signs of PID, ${ }^{7}$ while none of the patients with selective IgA deficiency showed this clinical manifestation, which supports the fact that warning signs favour an early diagnosis of PID during the case-taking process of pediatric patients.

The number of deaths caused by immunodeficiency was lower than that described in other patient series. ${ }^{4}$

A Candida sp. infection is a clinical manifestation generally associated with combined and phagocyte defects, ${ }^{1}$ however, in our study, it was found in patients with immune dysregulation alterations and innate immune defects.

The proportion of allergic disease in patients with selective IgA deficiency was higher than in the other PID group, and this is consistent with the literature, which indicates that atopy is the second most common clinical manifestation in these patients, after recurrent infections. ${ }^{14,15}$

The prevalence of autoimmune conditions was lower than that reported in other research studies. ${ }^{14}$

The study sample size and its retrospective design are restrictions that prevent us from drawing definitive conclusions regarding the conditions herein described.

\section{CONCLUSIONS}

The main clinical manifestation among patients with PID were respiratory tract infections. Allergic disease was a common clinical manifestation among patients with selective IgA deficiency.

Warning signs were present in severe PID cases.

Treatment of patients with severe PID was more complex than in patients with selective IgA deficiency.

\section{Acknowledgments}

We would like to thank Eugenia Concari, Technician, Arnaldo Mangeaud, M.D., and Marina F. Ponzio, M.D., for their collaboration in developing this research study.

\section{REFERENCES}

1. Notarangelo LD. Primary immunodeficiencies. J Allergy Clin Immunol 2010;125(2 Suppl 2):S182-94.

2. Al-HerzW, Bousfiha A, CasanovaJL, Chatila T, etal.Primary immunodeficiency diseases: an update on the classification from the International Union of Immunological Societies Expert Committee for Primary Immunodeficiency. Front Immunol 2014;5:162.

3. Grupo de Inmunología Pediátrica. Registro argentino de inmunodeficiencias primarias. Segundo informe. Arch Argent Pediatr 2007;105(5):453-60.

4. Gathmann B, Binder N, Ehl S, Kindle G. The European internet-based patient and research database for primary immunodeficiencies: update 2011. Clin Exp Immunol 2012;167(3):479-91.

5. De Vries E. Patient-centred screening for primary immunodeficiency: a multi-stage diagnostic protocol designed for non-immunologists. Clin Exp Immunol 2006;145(2):204-14.

6. Aghamohammadi A, Abolhassani H, Biglari M, Abolmaali $\mathrm{S}$, et al. Analysis of switched memory B cells in patients with IgA deficiency. Int Arch Allergy Immunol 2011;156(4):462-8.

7. Leiva LE, Bezrodnik L, Oleastro M, Condino-Neto A, et al. Primary immunodeficiency diseases in Latin America: proceedings of the second Latin American Society for immunodeficiencies (LASID) Advisory Board. Allergol Immunopathol (Madr) 2011;39(2):106-10.

8. Jeffrey Modell Foundation. 10 warning signs. New York: Jeffrey Modell Foundation; 2013. Available at: http:/ /www. info4pi.org/library/educational-materials /10-warningsigns. [Accessed on: May 16, 2014].

9. Conley ME, Notarangelo LD, Etzioni A. Diagnostic criteria for primary immunodeficiencies. Representing PAGID (Pan-American Group for Immunodeficiency) and ESID (European Society for Immunodeficiencies). Clin Immunol 1999;93(3):190-7.

10. EhlS. New clinical diagnosis criteria for the ESID Registry. Geneva: European Society for Immunodeficiencies; 2014. Available at: http:/ / esid.org/Working-Parties/Registry/ Diagnosis- criteria. [Accessed on: March 5, 2014].

11. Ballow M, Notarangelo L, Grimbacher B, CunninghamRundles C, et al. Immunodeficiencies. Clin Exp Immunol 2009;158(Suppl 1):14-22.

12. Costa-Carvalho BT, Grumach AS, Franco JL, EspinosaRosales FJ, et al. Attending to warning signs of primary immunodeficiency diseases across the range of clinical practice. J Clin Immunol 2014;34(1):10-22.

13. Joshi AY, Iyer VN,HaganJB,StSauverJL, etal. Incidence and temporal trends of primary immunodeficiency: a populationbased cohort study. Mayo Clin Proc 2009;84(1):16-22.

14. Domínguez O, Giner MT, Alsina L, Martín MA, et al. Fenotipos clínicos asociados a la deficiencia selectiva de IgA: revisión de 330 casos y propuesta de un protocolo de seguimiento. An Pediatr (Barc) 2012;76(5):261-7.

15. Yel L. Selective IgA deficiency. J Clin Immunol 2010;30(1):10-6. 